\title{
Influence of ethnic origin on the pattern of congenital heart defects in the first year of life
}

\author{
M Sadiq, O Stümper, J G C Wright, J V De Giovanni, C Billingham, E D Silove
}

\begin{abstract}
Objective-To assess the prevalence and patterns of congenital heart defects in infants requiring hospital admission in a defined population and to determine the differences in ethnic groups.
\end{abstract}

Design-A three year retrospective analysis of all hospital admissions for paediatric congenital heart defects in a single centre.

Setting-Tertiary referral centre for infant cardiac services in the West Midlands region, United Kingdom.

Patients and methods-Indian, Pakistani, Bangladeshi and other individuals from the Indian subcontinent constitute $5 \cdot 8 \%$ of the total population of the West Midlands region. Some $9 \%$ of infants, however, are Asian because of a high birth rate. All infants with confirmed congenital heart defects resident in this region who required hospital admission between April 1990 and March 1993 were classified as Asians and non-Asian, mainly white, infants.

Results-Of 1111 infants with congenital heart defects born in the West Midlands and admitted to the hospital, $17 \cdot 0 \%$ were Asian, significantly more than the percentage of Asian infants in the population $(P<0.0001)$. Asian infants had a higher proportion of complex congenital heart disease $(7 \% v 2.1 \%, P<0.001)$, whereas coarctation of the aorta was more common in non-Asian $(3 \%$ v $9.1 \%, P=$ 0.003). Persistent arterial duct seemed to be more common in Asian children (16\% $v 10 \%$, NS), but this group included preterm infants admitted for duct ligation. There was no significant difference between the two groups in the other nine categories of congenital heart defects.

Conclusions-The estimated prevalence of congenital heart defects requiring hospital admission was higher in Asian infants than in non-Asian (9.45 per $1000 v$ 4.56 per 1000, $P<0.0001)$. Complex congenital heart defects were more common in Asian infants whereas coarctation of the aorta was more common in nonAsian.

(Br Heart f 1995;73:173-176)

Keywords: congenital heart disease; ethnic origin; infancy.
The prevalence and pattern of specific congenital heart lesions in different ethnic groups is well documented. ${ }^{12}$ There are, however, few studies assessing the prevalence and pattern of congenital heart defects in different ethnic groups living in the same geographical area. The population of Indians, Pakistanis, Bangladeshis, and other individuals from the Indian subcontinent in the United Kingdom has increased over the past three decades $(1.8$ million in the census 1991) and Asians form $5.8 \%$ of the total population of the West Midlands region. ${ }^{34}$ The percentage $(9 \%)$ is even higher for children aged $0-4$ years.

The pattern of congenital heart defects in Asian infants requiring hospital admission over a period of three years was compared with that of mainly white infants. The purpose of the study was to provide comparable data on the prevalence and distribution of congenital heart defects in Asian and non-Asian infants. The data may be valuable for future healthcare planning, advice and as a basis for aetiological studies.

\section{Patients and methods}

The records of all the children under the age of 1 year with confirmed congenital heart defects admitted to the Children's Hospital, Birmingham between 1 April 1990 and 31 March 1993 were examined. The diagnosis of congenital heart defects was confirmed on echocardiography, cardiac catheterisation, surgery, or postmortem examination.

The Children's Hospital, Birmingham is the tertiary referral centre for infant cardiac services for the West Midlands region. The study was limited to the infants born and resident in the West Midlands region, and readmissions for the same admissions were not considered. A large population of Asians mainly from the Indian subcontinent live in this region. All infants were classified as Asian and non-Asian on the basis of ethnic origin. The non-Asian group consisted of whites, blacks (Caribbean and African) and remaining minority groups.

Population statistics for the region and the individual ethnic group were available from the Office of Population Censuses and Surveys and taken from Census 1991 Great Britain $^{3} 4$ (table 1). West Midlands Regional Health Authority uses the same boundaries as those described for the West Midlands region in the census.

Cardiac defects were divided into twelve 
Table 11991 Census based population data for the West Midlands region

\begin{tabular}{lc}
\hline Total population & 5150187 \\
Non-Asian & $4852358(94 \cdot 2)$ \\
White & $4725824(91 \cdot 8)$ \\
Black & $102206(2 \cdot 0)$ \\
Other & $24328(0 \cdot 5)$ \\
Asian & $297829(5 \cdot 8)$ \\
Indian & $158731(53 \cdot 3)$ \\
Pakistani & $98612(33 \cdot 1)$ \\
Bangladeshi & $19415(6 \cdot 5)$ \\
Other & $21071(7 \cdot 1)$ \\
Population data for infants aged $0-4$ years & \\
Total & $351241(6 \cdot 8)$ \\
Non-Asian & $314047(89 \cdot 4)$ \\
White & $302670(86 \cdot 2)$ \\
Black & $11377(3 \cdot 2)$ \\
Other & $5297(1 \cdot 5)$ \\
Asian & $31897(9 \cdot 1)$ \\
Indian & $13957(43 \cdot 7)$ \\
Pakistani & $13258(41 \cdot 6)$ \\
Bangladeshi & $2888(9 \cdot 0)$ \\
Other & $1794(5 \cdot 6)$ \\
\hline
\end{tabular}

Values in parenthesis are percentages.

diagnostic groups (table 2). The dominant defect was considered in infants who had more than one cardiac lesion. Ventricular septal defect, atrial septal defect, and atrioventricular septal defect were combined together under the term septal defects. Tetralogy of Fallot, pulmonary atresia with ventricular septal defect, double outlet right ventricle, and truncus arteriosus were grouped as conotruncal defects. Complex congenital heart disease included patients with single ventricle (double inlet left or right ventricle with or without outlet chamber) and infants with atrial isomerism. Pulmonary atresia with intact septum and tricuspid atresia were grouped as hypoplastic right heart. The aortic coarctation group also included infants with interruption of the aortic arch. Other lesions consisted of the disorders of heart rate and rhythm, vascular rings or slings, anomalies of the coronary arteries, and other rare isolated anomalies such as mitral valve disease and Ebstein's malformation.

Prevalence was calculated for the two

Table 2 Congenital heart defects in relation to diagnostic group and ethnic origin

\begin{tabular}{|c|c|c|c|}
\hline Diagnostic group & $\begin{array}{l}\text { No of Asian } \\
\text { infants }\end{array}$ & $\begin{array}{l}\text { No of non-Asian } \\
\text { infants }\end{array}$ & p Value \\
\hline All cases $(n=1111)$ & & & \\
\hline Septal defects & $49(26)$ & $274(29 \cdot 7)$ & 0.296 (NS) \\
\hline Ventricular septal defect & 33 & 176 & (3) \\
\hline Atrioventricular septal defect & 10 & 78 & \\
\hline Atrial septal defect & 6 & 20 & \\
\hline $\begin{array}{l}\text { Persistent ductus arteriosus } \\
\text { Preterm infants }\end{array}$ & $\begin{array}{l}30(16) \\
24\end{array}$ & $\begin{array}{l}92(10) \\
60\end{array}$ & $0 \cdot 018^{\star}$ \\
\hline Others & & & \\
\hline Conotruncal defects & $23(12)$ & $130(14 \cdot 1)$ & 0.483 (NS) \\
\hline Tetralogy of Fallot & 15 & 94 & \\
\hline $\begin{array}{l}\text { Pulmonary atresia with } \\
\text { yentricular septal defect }\end{array}$ & & & \\
\hline $\begin{array}{l}\text { ventricular septal defect } \\
\text { Double outlet right ventricle }\end{array}$ & 3 & 8 & \\
\hline $\begin{array}{l}\text { Double outlet right ventricle } \\
\text { Truncus arteriosus }\end{array}$ & 2 & 5 & \\
\hline Coarctation of the aorta & $5(3)$ & $84(9 \cdot 1)$ & $0.003^{\star \star}$ \\
\hline Transposition of great arteries & 20 (11) & $80(8 \cdot 7)$ & 0.404 (NS) \\
\hline Transposition (simple and complex) & 17 & 74 & \\
\hline Corrected transposition & & $29(3 \cdot 1)$ & \\
\hline Hypoplastic left heart & $6(3)$ & $29(3 \cdot 1)$ & 0.983 (NS) \\
\hline Anomalous pulmonary return & $5(3)$ & $23(2 \cdot 5)$ & 0.803 (NS) \\
\hline Complex congenital heart disease & $14(7)$ & $19(2 \cdot 1)$ & $<0.001^{\star \star \star}$ \\
\hline Hypoplastic right heart & $6(3)$ & $42(4 \cdot 5)$ & 0.395 (NS) \\
\hline Tricuspid atresia & 2 & 23 & \\
\hline Pulmonary atresia with intact septum & & 19 & \\
\hline $\begin{array}{l}\text { Aortic stenosis } \\
\text { Pulmos }\end{array}$ & $2(1)$ & $25(2 \cdot 7)$ & $0 \cdot 295$ (NS) \\
\hline Pulmonary stenosis & $4(2)$ & $30(3 \cdot 2)$ & 0.408 (NS) \\
\hline Other lesions & $23(12)$ & $94(10 \cdot 2)$ & $0.421(\mathrm{NS})$ \\
\hline
\end{tabular}

Values in parenthesis are percentages

$\star$ Significant at $5 \%$ level; ${ }^{\star}$ Significant at the $1 \%$ level; ${ }^{\star} \star$ Significant at the $0 \cdot 1 \%$ level. NS, no significant at the $5 \%$ level. groups by using the total population of infants in the region in the 1991 census as the denominator. Statistical analysis was performed using the $\chi^{2}$ test.

\section{Results}

Of 1111 infants with confirmed congenital heart defects admitted to the Children's Hospital from the West Midlands region during the 3 year period, $189(17 \cdot 0 \%)$ were Asian and $922(83.0 \%)$ non-Asian. Some 74000 children under the age of 1 year were resident in the West Midlands region in 1991. ${ }^{34}$ The census showed that $9 \%$ of children under the age of 4 years in the region were Asian (table 1). The census did not give the ethnic breakdown for infants, and we have assumed the same percentage as for children under the age of 4. Annual prevalence using these data is estimated to be 9.45 per 1000 for Asian infants and 4.56 per 1000 for non-Asian infants. This difference between the two groups is highly significant $(P<0.0001)$. If preterm infants with persistent arterial duct are excluded from the total cohort of admissions the difference remains significant (Asian infants $=8.34$ per $1000 v$ non-Asian infants $=$ 4.4 per $1000, P<0.001)$. The overall annual prevalence for West Midlands region is estimated as 5.0 per 1000 population.

Table 2 shows the pattern of distribution of individual congenital heart defects. Septal defects were the most common lesions in both groups. There was a significantly higher proportion of admissions for complex congenital heart disease $(P<0.001)$ in Asian than in non-Asian infants. In contrast, non-Asian infants had a high proportion of admissions for coarctation of the aorta $(P=0.003)$ compared with that of Asian infants. The proportion of admissions for persistent arterial duct seemed to be higher in Asian infants than in non-Asian infants $(P=0.018)$, but was not statistically significant when Bonferroni correction was used. Most infants in this group were preterm and admitted for duct ligation. There was no difference in the proportion of persistent arterial duct between the two groups if preterm infants were excluded. There was no significant difference in the pattern of the other nine categories of congenital heart defects between the two groups.

The statistical analyses in table 2 are unadjusted for the fact that twelve significance tests were carried out. If Bonferroni correction is used then the tests for coarctation of the aorta and complex congenital heart disease remain significant, whereas that for persistent arterial duct is no longer significant.

Chromosomal anomalies were present in $7 \cdot 1 \%$ of all infants. Down's syndrome was the most common anomaly equally affecting the two groups $(6 \cdot 2 \%$ of Asian infants and $6.3 \%$ of non-Asian infants).

\section{Discussion}

The influence of ethnic origin on the prevalence of congenital heart defects requiring 
hospital admission in infancy was investigated in the present study. There is a defined geographical area with a known population and a single tertiary referral centre providing paediatric cardiac services for the entire area. Population data were obtained from a recent census which was carried out during the study period. As cardiovascular abnormalities may not be immediately evident in the neonatal period, recent epidemiological studies ${ }^{5-7}$ have used a 1 year diagnostic window during which the most serious congenital abnormalities will be identified. A limitation to the study is that the census did not give the ethnic breakdown for children under the age of 1 year and we have assumed the same percentage as for children under the age of 4 years. This is compounded by an undernumeration of around $2 \%$ in the 1991 census. $^{89}$ The underestimate for infants aged 0-4 years, as in the present study, was around 3\% for England and Wales, which is unlikely to be significant in relation to the overall data. No separate breakdown was available for the West Midlands region. A comparison between estimates of the population by ethnic group in the census and the Labour Force Survey ${ }^{8}$ shows, however, that under enumeration is not biased towards ethnic minority groups ${ }^{8}$ and data are as reliable as one could expect in a survey of this nature.

Our data show that the prevalence of congenital heart defects in infants requiring hospital admission in the West Midlands region is 5.0 per 1000 population. Previous studies of the prevalence of congenital heart defects show major variations in the rate of congenital heart defects in the first year of life. The Baltimore-Washington study infant ${ }^{5}$ was limited to infants born alive with the diagnosis of congenital heart defect confirmed during the first year of life by echocardiography, cardiac catheterisation, cardiac surgery, or postmortem examination. The reported prevalence of 3.7 per 1000 live births was constant over the past 40 years. The Heritage paediatric cardiology program, ${ }^{7}$ using the same entry criteria, revealed a higher rate of 5.54 per 1000 live births. The New England regional infant cardiac program ${ }^{6}$ used invasive diagnostic criteria (cardiac catheterisation, cardiac surgery, or postmortem examination) and reported a rate of $2 \cdot 2$ per 1000 live births for paediatric cardiac defects. Dickinson et al ${ }^{10}$ from Liverpool reported an incidence of 5.51 per 1000 live births over a period of 10 years. We examined only the infant hospital admissions and found a prevalence of 5.0 per 1000 population. The rate is very high for children of Asian parents compared with that for infants of non-Asian parents $(9.45$ per $1000 v$ 4.56 per $1000, P<0.0001)$. A high rate of congenital malformations including cardiac defects in Asian children has been reported in the literature, ${ }^{11}$ but to our knowledge no studies have investigated the pattern of congenital heart defects in Asian and non-Asian children.

Septal defects were the most common lesions in both groups and there was no significant difference in the comparative proportions. Preterm infants with persistent arterial duct requiring duct ligation were included in our study. The apparent higher proportion of this lesion in the Asian population was probably caused by a high rate of prematurity in Asians from a low socioeconomic and poor nutritional background and an increased incidence of rubella among Asians of England and Wales. ${ }^{12} 13$ There was no difference in the proportion of persistent arterial duct between the two groups when preterm infants were excluded. The overall high prevalence of congenital heart defects in Asian infants persisted, however, even if preterm infants with persistent ductus arteriosus were excluded from the total admissions.

Analysis of the data on left sided obstructive lesions yielded no significant difference between the two groups in the categories of aortic stenosis or hypoplastic left heart syndrome. Coarctation of the aorta and interruption of the aortic arch, however, were significantly higher in non-Asian infants than in Asian infants. Interestingly, Villasenor et $a l^{1}$ in the Baltimore-Washington infant study found a higher prevalence of aortic stenosis and coarctation of the aorta in whites compared with that in blacks. Data on the relative prevalence of various types of congenital heart defects in different racial groups in Asia ${ }^{14-16}$ also show low proportions of coarctation of the aorta in Asian children. Anderson ${ }^{17}$ reported this low proportion in American Indians and cited similar low proportions in Asians from Japan, Korea, and Thailand. He suggested a common genetic factor. Others, ${ }^{18}$ however, have suggested that inadequate diagnosis is responsible for the apparently low incidence in Asians. All our patients were from the same area and had a similar pattern of referral, therefore the risk of underdiagnosis in Asians is unlikely.

Complex congenital heart disease with atrial isomerism was significantly higher in Asian infants. Gatrad et al ${ }^{19}$ found a high incidence of complex congenital heart disease with visceral hetreotaxia in the Muslim Pakistani populations of Manchester and Leeds. This was associated with a very high incidence of parental consanguinity that was even higher than in the general Muslim Asian population of that area. We did not have complete data on the incidence of parental consanguinity for these infants but Bundey et $a^{20}$ found a high prevalence $(69 \%)$ of parental consanguinity in the Pakistani Muslims of Birmingham and the degree of inbreeding was greater than that for first cousin parents. A recessive genetic component as suggested by Gatrad et al ${ }^{19}$ may be involved in the aetiology of complex congenital heart defects.

The difference in the prevalence of congenital heart defects between Asian and nonAsian infants is striking. If a generally lower nutritional and socioeconomic status of the Asian population is responsible for these higher overall rates then one would expect its effect to be present uniformly for each abnormality. This obviously is not the case. Although it was not possible to obtain data on the incidence of parental consanguinity in the 
present study, it is likely that it was high in the Asian Muslim population within our study. ${ }^{20}$ This may be an important factor responsible for the high prevalence of congenital heart defects in this group, although racial factors other than consanguinity could also be responsible.

In conclusion, this study has shown a significant difference in congenital heart defects between Asian and non-Asian infants. The prevalence of congenital heart defects requiring hospital admission was higher in Asian infants than in non-Asian. Complex congenital heart defects were more common in Asian infants, whereas coarctation of the aorta was more common in non-Asian children. Persistent arterial duct seemed to be more common in Asian infants but was probably related to a higher prevalence of prematurity.

1 Villasenor AC, McCarter R, Ferencz C. White-black differences in cardiovascular malformations in infancy and socioeconomic factors. Am $f$ Epidemiol 1991;134: 393-402.

2 Tatsmo K, Ando M, Takan A, et al. Diagnostic importance of aortography in conal ventricular septal defects. Am Heart f 1975;89:171-7.

3 Office of Population Censuses and Surveys. Census 1991; ethnic group of residents. London: Her Majesty's Sthnic group of residents. London:

4 Office of Population Census and Surveys. Census 1991; metropolitan counties, Inner London, Outer London, regional metropolitan counties, Inner London, Outer London, regional
remainders, Wales, Scotland. London: Her Majesty's Stationery Office, 1991. (Part 1, page 153.)
5 Ferencz C, Rubin JD, McCarter RJ, et al. Congenital heart Washington Infant Study. Am $\mathcal{f}$ Epidemiol 1985;121: 31-6.

6 Fyler DC. Report of the New England Regional Infant Cardiac Program. Paediatrics 1980;65(suppl):375-461.

7 Grabitz RG, Joffers MR, Collins-Nakai RL. Congenital heart disease: incidence in the first year of life. $A m \mathcal{F}$ Epidemiol 1988;128:381-8.

8 Office of Population Censuses and Surveys. Undercoverage in Great Britain. London: Her Majesty's Stationery Office, 1994. (OPCS 1991 census user guide no 58.)

9 Raleigh VS, Balarajan R. Public health and the 1991 census: non-random underenumeration complicates interpretation. $B M F$ 1994;309:287-8.

10 Dickinson DF, Arnold R, Wilkinson JL. Congenital heart disease among 160480 liveborn children in Liverpoo 1960 to 1969 . Implications for surgical treatment. $B r$ Heart f 1981;46:55-62.

11 Terry PB, Bissenden JG, Condie RG, et al. Ethnic differences in congenital malformations. Arch Dis Child 1985; 60:866-8.

12 Miller E, Nicoll A, Rouseau SA, et al. Congenital rubella in babies of south Asian women in England and Wales: an in babies of south Asian women in England and

13 Campbell $M$. Place of maternal rubella in the aetiology of congenital heart disease. $B M \mathcal{F}$ 1961;1:691-4.

14 Pai BV, Varkey CC. Spectrum of congenital heart disease in general hospital. Study of 200 cases. Indian $\mathcal{F}$ Pediatr 1974;41:317-21.

15 Wallooppillai NJ, Jayesinghe $M$ de S. Congenital heart disease in Ceylon. Br Heart $\mathcal{f} 1970 ; 32: 304-6$.

16 Shann MKM. Congenital heart disease Republic of China. Circulation 1969;39:251-8.

17 Anderson RC. Congenital heart malformations in North American Indian children. Paediatrics 1977;59:121-3.

18 van der Horst RL, Gotsman MS. Racial incidence of coarctation of the aorta. Br Heart F 1972;34:289-94.

19 Gatrad AR, Read AP, Watson GH. Consanguinity and complex cardiac anomalies with situs ambiguous. Arch Dis Child 1984;59:242-5.

20 Bundey S, Alam H, Kaur A, et al. Race, consanguinity and social features in Birmingham babies: a basis for prospective study. $\mathcal{F}$ Epidemiol Community Health 1990; 44:130-5. 